\title{
The psychophysiological effects of the COVID-19 quarantine in the college students
}

\author{
Yusuf Soylu ${ }^{\mathrm{ABCDE}}$ \\ Faculty of Sport Sciences, Tokat Gaziosmanpasa University, Turkey
}

Authors' Contribution: A - Study design; B - Data collection; C - Statistical analysis; D - Manuscript Preparation; E - Funds Collection.

\begin{abstract}
Background A global pandemic affected by COVID-19 resulted in restrictions to daily routines, including recreation and Study Aim activities, social skills, and academic and health quality of college students. This study aimed to evaluate the psychophysiological effect of coronavirus quarantine on physical activity and its' relationship between sleep quality, mood states and musculoskeletal pain in college students.

Material and $\quad$ A total of 392 (male $=150$; female $=242$; age $=22.9 \pm 5.5$ ) college students completed an online survey. The Methods International Physical Activity Questionnaire-Short Form (IPAQ-SF), the Brunel Mood Scale, the Pittsburgh Sleep Quality Index (PSQI) and the Visual Analogue Scale for musculoskeletal pain (MSP) were used in this study.

Results Total physical activity significantly correlation with PSQI $(p<0.05, r=-.103)$, fatigue $(p<0.01, r=-.344)$, depression $(p<0.01, r=-.258)$, angry $(p<0.01, r=-.210)$, vigour $(p<0.01, r=-.344)$, neck and shoulder, upper and lower back $(p<0.01, r=-.225)$, neck and shoulder correlation $(p<0.01, r=-.230)$, upper and lower back $(p<0.01, r=-.209)$. Furthermore, a positive correlation was shown between PSQI and negative moods and a negative correlation with positive mood.

Conclusions: During quarantine, decreased physical activity was associated with higher negative mood states and poor sleep quality and more MSP. The COVID-19 quarantine has considerably affected mental health-related crisis consists of desperation, self-consciousness and deficiency of physical capabilities in young adults, especially in college students.

Keywords: COVID-19, physical activity, sleep quality, mood, musculoskeletal pain
\end{abstract}

\section{Introduction}

COVID-19 is a mortal disaster that is spreading human to human infectious disease all over the world. The pandemic of the coronavirus tried to control taking precautions such as mask, social distance [1]. However, increased death rate in many countries created a solution to the transmission of the virus with various restrictions including travelling, closing the school and home confinement [2]. Not only these restrictions prevent infecting coronavirus, but also negatively affected public health decreasing physical activity level [3] and attending sports organizations [4]. Physical activity and nutrition linked to the immune system and its relationship provide to prevent COVID-19 as all viral disease $[5,6]$. Thus, coronavirus might lead to changing levels of physical activity, related to psychophysiological responses, mood states, sleep quality and musculoskeletal pain during the lockdown.

Health is the most important factors in the quality of life and it is possible that improving physical fitness components [7]. Restrictions of outdoor activities in some countries could make a difficult to enhance the level of physical activity [1]. Therefore, these restrictions negatively were composed to a potential risk for physical fitness, infections and critical immunologic and cardiopulmonary [8,9], depression [10] and obesity [11].

C) Yusuf Soylu, 2021

doi:10.15561/20755279.2021.0303
Restrictions of physical and social activities may cause negative mood states to consist of stress, tension, anxiety, sleep disorder, physiological stress in quarantine [12, 13]. Conversely, physical activity positively affected healthrelated physical parameters and well-being and increasing well-being in college students [14, 15].

Previous studies $[14,16]$ shown a significant reduction in physical activity behaviour and participation among college students in low-, middle- and highincome countries. Physical activity could avoid harmful effect on mental health, stress, anxiety to college students [17, 18]. Considering, physical education classes, transportation, social activities provide higher physical activity, COVID-19 may reveal many problems to college students. According to American College Health Association [19] reported, COVID-19 imposed mental health challenges, clarifying stress, depression and anxiety which is important factors of academic achievement. Similarly, physical activity might use a tool coping with mental health problems during COVID-19 [20]. Given the evidence presenting coronavirus higher impact physical inactivity and would mediating effect mental health psychological and physical disorder. Taken together, the aim of this study investigates the relationship between physical activity and psychophysiological (mood state, sleep quality) and physical effects (MSP) in college students. 


\section{Materials and Methods}

Participants.

Total of 392 college students $(n=150$ male and $n=$ 242 female; age $=22.9 \pm 5.5$ ) participated in the present study. All socio-demographic variables of students were identified in Table 1. Before completing questionnaires, students informed about the study, voluntarily participating, and was used an online questionnaire form. This study was approved by Tokat Gaziosmanpasa University (Turkey) ethical committee (E-33490967-04422125) and all procedures conducted were accordance in with the Declaration of Helsinki.

Research Design

Measures

Physical Activity Questionnaire-Short Form (IPAQ$S F)$. The IPAQ-SF, which is a validated and reliable tool, was used to measure levels of PA [21], adapted by Saglam et al. [22]. IPAQ-SF is seven items self-administered questionnaire to measured daily activities including walking-moderate and vigorous activity. Participants required recalling their intensity of physical activity in the last week. Each activity performed, clarifying eligibility criteria, at least ten minutes at a time. PA results (METmin.week-1) was used to assess total weekly and the metabolic equivalent task (MET) minute for each item was calculated according to the scoring protocol (walking 3.3 METs, moderate 4 METs, vigorous 8 METs).

Pittsburgh Sleep Quality Index (PSQI). Pittsburgh Sleep Quality Index was widely used to measure sleep quality reported during the previous 4 weeks [23]. Agargün et al. [24] translated it to Turkish. The PSQI questionnaire has 19 items that assess 7 subcategories of sleep: subjective quality, latency, duration, habitual efficiency, disturbance, use of sleeping medication, and daytime dysfunction. The PSQI questionnaire score > 5 (max. score is 21) determines poor sleep quality.

Brunel Mood Scale. Participant completed the Brunel Mood Scale (BRUMS) was developed by Terry et al. $[25,26]$ including 24 items and 6 subscales (tension, mood depression, anger, vigour, fatigue, and confusion). Cakiroglu et al. [27] was translated the Turkish version of BRUMS and it has 19 items 4 subscales (fatigue, depression, anger and vigour). Each item score ranging from 0 (none) to 4 (extremely) and the total score ranges from 0 to 16 .

Visual Analogue Scale (VAS). The musculoskeletal pain and severity within the past one week were calculated by a self-completed self-report visual analogue scale (100-mm) [28].

Statistical Analysis.

Data was calculated mean \pm standard deviation. Pearson's correlation coefficient analysis evaluated the relationship between PA and PSQI, mood profiles and MSP. Multiple linear regression was used to identify the effect of PA on PSQI, mood profiles and MSP. Correlation coefficient thresholds were assessed according Schober et al. [29]. Statistical analyses were performed with SPSS package version 24.0 (SPSS, Version 24.0 for Windows; SPSS Inc., Chicago, IL, United States). All analysis of significance level was set at $\mathrm{p} \leq 0.05$ and $\mathrm{p} \leq 0.01$ respectively.

\section{Results}

In this part of the study, results have been presented PA, PSQI, mood states and MSP responses on college students in COVID-19. Relationship among physical activity, sleep quality, mood states and musculoskeletal pain was shown in Table 2 . The lower physical activity and higher musculoskeletal pain were related to poor sleep quality and negative mood states. The physical activity was associated with outcome of sleep quality, mood states and musculoskeletal pain, regression analyses were conducted in Table 3. The level of physical activity was significantly associated with fatigue and vigour.

Table 1. Descriptive characteristics of university students

\begin{tabular}{ll}
\hline Characteristics $(\mathbf{n = 3 9 2 )}$ & Mean \pm SD \\
\hline Age $_{(\text {year })}$ & $22.9 \pm(5.5)$ \\
Height $_{(\mathrm{cm})}$ & $170.1 \pm(8.8)$ \\
Weight $_{(\mathrm{kg})}$ & $64.5 \pm(13.1)$ \\
BMI $_{(\mathrm{kg} / \mathrm{m} 2)}$ & $22.1 \pm(3.2)$ \\
\hline
\end{tabular}

Musculoskeletal Pain

Neck and shoulder, upper and $2.9 \pm(2.6)$

lower back

Neck and shoulder $\quad 2.8 \pm(2.6)$

Upper and lower back $\quad 2.9 \pm(2.7)$

International Physical Activity

Questionnaire-Short Form (IPAQ-

SF

$\begin{array}{ll}\left.\mathrm{IPAQ}_{\text {light(min }}{ }^{-2} / \text { week }\right) & 480.9 \pm(300.2) \\ \mathrm{IPAQ}_{\text {moderate(min-2/week) }} & 259.0 \pm(305.4) \\ \mathrm{IPAQ}_{\text {high(min-2/week })} & 237.3 \pm(256.2) \\ \mathrm{IPAQ}_{\text {total(min }}{ }^{-2} \text { (week) } & 1092.6 \pm(678.8)\end{array}$

Pittsburgh Sleep Quality Index

(PSQI)

\begin{tabular}{ll}
\hline Subjective sleep quality & $1.3 \pm(0.8)$ \\
Sleep Latency & $2.6 \pm(1.8)$ \\
Sleep Duration & $0.5 \pm(0.9)$ \\
Habitual Sleep Efficiency & $1.0 \pm(1.3)$ \\
Sleep Disturbances & $1.5 \pm(0.7)$ \\
Use of Sleep Medication & $0.9 \pm(0.9)$ \\
Daytime Dysfunction & $2.2 \pm(1.1)$ \\
Sleep Quality & $8.1 \pm(3.5)$ \\
\hline Mood & \\
\hline Fatigue & $2.2 \pm(1.1)$ \\
Depression & $2.3 \pm(1.1)$ \\
Anger & $2.1 \pm(1.1)$ \\
Vigor & $1.6 \pm(0.9)$ \\
\hline
\end{tabular}




\section{Discussion}

The current study assessed the effects of quarantine on physical activity, PSQI, mood state profile and MSP during the COVID-19 pandemic. As expected, the quarantine was changed the psychophysiological responses and health of students as they exhibited low intensity in physical activity, poor sleep quality, increasing negative moods and higher musculoskeletal pain.

The lifestyle of college, including transportation, physical education class, social activities, may contribute physical and psychological health of students. This study results explain that during the COVID-19 home confinement process, there has been a reduction in walking, moderate, vigour and total PA levels, PSQI, mood and increasing MSP in college students. Current researches $[1,30]$ demonstrated that physical activity levels decrease during quarantine consist of higher sitting time at home. Previous studies presented that student might home-based activity during home confinement such as active short breaks, walking around the house, and self-paced exercise [31, 32]. Therefore, when the daily behaviour of people changes some restrictions, psychological factors might affect physiological and metabolically factors consist of poor sleep quality and MSP pain. A recent systematic review revealed that one of the effective and non-pharmacological methods of improving sleep quality is physical activity [33]. Students could eliminate depressive symptoms through regular physical activity and increasing sleep quality [34]. It is well-known that improving well-being, sleep quality and lifestyle behaviours might play a key role [33]. Physical inactivity and sleep disorder can impair mentally such as mental fatigue. Abdulah and Musa (2020) [35] determined that sleep habits could regulate immune functions and together improving the immune system responding to antigen.

Concerning, students practice same activities all day home lockdown during COVID-19, including long sitting time, social media addiction, watching TV, might lead to appear cognitive disorder which is named mental fatigue. Mental fatigue could characterize a psychobiological state as a lack of energy and tiredness as a result of the prolonged activity [36]. According to Ishii et al. [37] while mental fatigue arouses inhibitory system in brain function with increasing mental exertion, this situation would create decreasing motivation and willingness.

Regarding recent studies of physical activity and mood disorders in home confinement $[34,4,12]$ mentioned that mood disorders associated with physical inactivity. This study results showed that when the students experienced vigour, the level of physical activity and sleep quality increased. In contrast to positive mood, decreasing sleep quality and physical activity are a positive relationship with negative moods such as depression, tension and fatigue. Negative mood states (depression, anxiety, stress) could alter psychological wellbeing with time spent in the

Table 2. Association among IPAQ, PSQI and Moods and MSP (Pearson Correlation Coefficient)

\begin{tabular}{|c|c|c|c|c|c|c|c|c|c|c|}
\hline Nc & Characteristics & 1 & 2 & 3 & 4 & 5 & 6 & 7 & 8 & 9 \\
\hline 1 & $\mathrm{IPAQ}_{\text {total(min/week) }}$ & 1 & $-.103 *$ & $-.344 * *$ & $-.258 * *$ & $-.210 * *$ & $.463 * *$ & $-.225 * *$ & $-.230 * *$ & $-.209 * *$ \\
\hline 2 & PSQI & & 1 & $.460 * *$ & $.380 * *$ & $.377 * *$ & $-.211 * *$ & $.390 * *$ & $.370 * *$ & $.435 * *$ \\
\hline 3 & Fatigue & & & 1 & $.851^{* *}$ & $.797^{* *}$ & $-.630 * *$ & $.397 * *$ & $.376 * *$ & $.386 * *$ \\
\hline 4 & Depression & & & & 1 & $.857^{* *}$ & $-.594 * *$ & $.294^{* *}$ & $.289 * *$ & $.294 * *$ \\
\hline 5 & Angry & & & & & 1 & $-.503 * *$ & $.266 * *$ & $.254 * *$ & $.280 * *$ \\
\hline 6 & Vigour & & & & & & 1 & $-.315^{* *}$ & $-.271 * *$ & $-.311 * *$ \\
\hline 7 & $\begin{array}{l}\text { Neck and shoulder, upper and lower } \\
\text { back }\end{array}$ & & & & & & & 1 & $.811^{* *}$ & $.802^{* *}$ \\
\hline 8 & Neck and shoulder & & & & & & & & 1 & $.695 * *$ \\
\hline 9 & Upper and lower back & & & & & & & & & 1 \\
\hline
\end{tabular}

Table 3. Multiple Regression Analysis on the Predictor of Physical Activity

\begin{tabular}{|c|c|c|c|c|c|c|}
\hline No & Characteristics & $\mathbf{R}^{2}$ & $\Delta \mathbf{R}^{2}$ & $\boldsymbol{\beta}$ & $\mathbf{t}$ & $\mathbf{F}$ \\
\hline 1 & PSQI & .245 & .229 & .061 & 1.152 & 15.501 \\
\hline 2 & Fatigue & & & $-.274 *$ & -2.810 & \\
\hline 3 & Depression & & & .145 & 1.387 & \\
\hline 4 & Angry & & & .094 & 1.045 & \\
\hline 5 & Vigour & & & $.410 *$ & 6.958 & \\
\hline 6 & Neck and shoulder, upper and lower back & & & .019 & .210 & \\
\hline 7 & Neck and shoulder & & & -.116 & -1.508 & \\
\hline 8 & Upper and lower back & & & -.006 & -.078 & \\
\hline
\end{tabular}


quarantine [4]. Physiology of mood, including serotonin, dopamine and adrenaline, linked to play an active role in the psychological and behavioural process that is these neurotransmitters related to activating happiness, pleasure and regulating mood and energy [38, 39]. Lack of physical activity might occur deterioration of the physiological process during the lockdown. However, students would have difficulties regulating emotions, which causes poor physical and mental health.

Results of musculoskeletal pain examined levels of pain significantly increased with physical inactivity, irregulating mood state and sleep. Students would spend their times sitting activities such as video-game, using smartphone and watching TV during home confinement. In the literature previous studies showing that prolonged static activities, including sitting and screen-based activities may increase the risk of neck and shoulder pain, upper and lower back pain risk [40, 41].

\section{Conclusion}

In conclusion, not only physical activity is a key component of physical and psychological well-being

1. Papaspanos N. Effects of COVID-19 Home
Confinement on Eating Behaviour and Physical
Activity: Results of the ECLB-COVID19 International
Online Survey. Komp Nutr Diet, 2021;1:19-21.
https://doi.org/10.1159/000512852

2. Parnell D, Widdop P, Bond A, Wilson R. COVID-19, networks and sport. Managing Sport and Leisure, 2020:1-7. https://doi.org/10.1080/23750472.2020.1750100

3. Hossain MM, Sultana A, Purohit N. Mental health outcomes of quarantine and isolation for infection prevention: A systematic umbrella review of the global evidence. Epidemiol Health, 2020:e2020038. https://doi.org/10.4178/epih.e2020038

4. Turgut M, Soylu Y, Metin SN. Physical activity, night eating, and mood state profiles of athletes during the COVID-19 pandemic. Progr Nutr, 2020;22(2-S):e2020019. https://doi.org/10.23751/pn.v22i2-S.10567

5. Li X, Geng M, Peng Y, Meng L, Lu S. Molecular immune pathogenesis and diagnosis of COVID-19. Journal of Pharmaceutical Analysis, 2020;10:102-8. https://doi.org/10.1016/j.jpha.2020.03.001

6. Ravalli S, Musumeci G. Coronavirus Outbreak in Italy: Physiological Benefits of Home-Based Exercise During Pandemic. J Funct Morphol Kinesiol. 2020;5:31. https://doi.org/10.3390/jfmk5020031

7. Bize R, Johnson JA, Plotnikoff RC. Physical activity level and health-related quality of life in the general adult population: A systematic review. Preventive Medicine, 2007;45:401-15. https://doi.org/10.1016/j.ypmed.2007.07.017

8. Bloch W, Halle M, Steinacker J. Sport in Zeiten von Corona [Sport in times of Corona]. Dtsch Z Sportmed, 2020;71:83-4. (In German). https://doi.org/10.5960/dzsm.2020.432

9. Steinacker J, Bloch W, Halle H, Mayer F, Meyer T, Hirschmüller A, et al. Fact Sheet: Health Situation for Athletes in the Current Coronavirus Pandemic (SARSCoV-2 / COVID-19). Dtsch Z Sportmed, 2020;71:85-6. https://doi.org/10.5960/dzsm.2020.431 daily routines of students but also unexpected times such as COVID-19. The current study presented that while physical activity is a positive relationship between positive mood states, negative relationship with quality of sleep and MSP. COVID-19 process highlighted that student might not ready against unexpected disease and disorder, the face of many negative outcomes. Further studies interested in examining the relationship between physical activity and the stress of academic success, hopelessness in the light of future anxiety in COVID-19.

\section{Acknowledgements}

This study was written by abridging Yusuf Soylu. No grants or financial aids were taken in this Project.

\section{Financial support}

There is no financial support.

\section{Conflict of interest}

The authors declare no conflict of interest

10.Rebar AL, Stanton R, Geard D, Short C, Duncan MJ, Vandelanotte C. A meta-meta-analysis of the effect of physical activity on depression and anxiety in non-clinical adult populations. Health Psychology Review, 2015;9:366-78. https://doi.org/10.1080/17437199.2015.1022901

11. Wanner M, Richard A, Martin B, Faeh D, Rohrmann S. Associations between self-reported and objectively measured physical activity, sedentary behavior and overweight/obesity in NHANES 2003-2006. Int $J$ Obes, 2017;41:186-93. https://doi.org/10.1038/ijo.2016.168

12.Asmundson GJG, Paluszek MM, Landry CA, Rachor GS, McKay D, Taylor S. Do pre-existing anxiety-related and mood disorders differentially impact COVID-19 stress responses and coping? Journal of Anxiety Disorders, 2020;74:102271. https://doi.org/10.1016/j.janxdis.2020.102271

13.Hammami A, Harrabi B, Mohr M, Krustrup P. Physical activity and coronavirus disease 2019 (COVID-19): specific recommendations for home-based physical training. Managing Sport and Leisure, 2020:1-6. https://doi.org/10.1080/23750472.2020.1757494

14.Wang J. The association between physical fitness and physical activity among Chinese college students. Journal of American College Health, 2019;67:602-9. https://doi.org/10.1080/07448481.2018.1515747

15. Warburton DER, Bredin SSD. Reflections on Physical Activity and Health: What Should We Recommend? Canadian Journal of Cardiology, 2016;32:495-504. https://doi.org/10.1016/j.cjca.2016.01.024

16.Wang C, Chen P, Zhuang J. Validity and Reliability of International Physical Activity QuestionnaireShort Form in Chinese Youth. Research Quarterly for Exercise and Sport, 2013;84:S80-6. https://doi.org/10.1080/02701367.2013.850991

17.Physical Activity Guidelines Advisory Committee. 2018 Physical Activity Guidelines Advisory Committee Scientific Report. Washington, DC: U.S. Department of Health and Human Services; 2018.

18.Hill MD, Gibson A-M, Wagerman SA, Flores ED, Kelly LA. The effects of aerobic and resistance exercise on state anxiety 
and cognitive function. Science \& Sports, 2019;34:216-21. https://doi.org/10.1016/j.scispo.2018.09.004

19.American College Health Association. American College Health Association-National College Health Assessment II: Reference Group Executive Summary Spring 2019. Silver Spring, MD: American College Health Association; 2019.

20.Maher JP, Hevel DJ, Reifsteck EJ, Drollette ES. Physical activity is positively associated with college students' positive affect regardless of stressful life events during the COVID-19 pandemic. Psychology of Sportand Exercise, 2021;52:101826. https://doi.org/10.1016/j.psychsport.2020.101826

21.Craig CL, Marshall AL, Sjöström M, Bauman AE, Booth ML, Ainsworth BE, et al. International Physical Activity Questionnaire: 12-Country Reliability and Validity. Medicine \& Science in Sports \& Exercise, 2003;35:1381-95. https://doi.org/10.1249/01.MSS.0000078924.61453.FB

22.Saglam M, Arikan H, Savci S, Inal-Ince D, BosnakGuclu M, Karabulut E, et al. International Physical Activity Questionnaire: Reliability and Validity of the Turkish Version. Percept Mot Skills, 2010;111:278-84. https://doi.org/10.2466/06.08.PMS.111.4.278-284

23.Buysse DJ, Reynolds CF, Monk TH, Berman SR, Kupfer DJ. The Pittsburgh sleep quality index: A new instrument for psychiatric practice and research. Psychiatry Research, 1989;28:193-213. https://doi.org/10.1016/0165-1781(89)90047-4

24.Agargün YM, Kara H, Anlar Ö. Pittsburgh Uyku Kalitesi İndeksinin geçerlilik ve güvenirliğI [Validity and reliability of the Pittsburgh Sleep Quality Index]. Türk Psikiyatri Dergisi, 1996. 7(2): 107-111. (In Turkish).

25.Terry PC, Lane AM, Fogarty GJ. Construct validity of the Profile of Mood States - Adolescents for use with adults. Psychology of Sport and Exercise, 2003;4:125-39. https://doi.org/10.1016/S1469-0292(01)00035-8

26.Terry PC, Lane AM, Lane HJ, Keohane L. Development and validation of a mood measure for adolescents. Journal of Sports Sciences 1999;17:861-72. https://doi.org/10.1080/026404199365425

27.Cakiroglu AA, Demir E, Guclu M. The Validity and Reliability Study of the Brunel Mood Scale with the Adult Athletes (Turkish Adaptation). Int. J. Appl. Exerc. Physiol. 2020. 9(10):126-40.

28.Bijur PE, Silver W, Gallagher EJ. Reliability of the Visual Analog Scale for Measurement of Acute Pain. Acad Emergency Med, 2001;8:1153-7. https://doi.org/10.1111/j.1553-2712.2001.tb01132.x

29. Schober P, Boer C, Schwarte LA. Correlation Coefficients: Appropriate Use and Interpretation. Anesthesia \& Analgesia, 2018;126:1763-8. https://doi.org/10.1213/ANE.0000000000002864
30. Orgilés M, Morales A, Delvecchio E, Mazzeschi C, Espada JP. Immediate PsychologicalEffects of the COVID-19Quarantine in Youth From Italy and Spain. Front Psychol 2020;11:579038. https://doi.org/10.3389/fpsyg.2020.579038

31.Garcia M, Custodio E. Home quarantine - based rhythmic exercises: new fitness assessment and intervention in teaching physical education. Physical Education of Students. 2021;25(1):51-7. https://doi.org/10.15561/20755279.2021.0107

32.Ricci F, Izzicupo P, Moscucci F, Sciomer S, Maffei S, Di Baldassarre A, et al. Recommendations for Physical Inactivity and Sedentary Behavior During the Coronavirus Disease (COVID-19) Pandemic. Front Public Health, 2020;8:199. https://doi.org/10.3389/fpubh.2020.00199

33.Wang F, Boros S. The effect of physical activity on sleep quality: a systematic review. European Journal of Physiotherapy, 2021;23:11-8. https://doi.org/10.1080/21679169.2019.1623314

34.Cahuas A, He Z, Zhang Z, Chen W. Relationship of physical activity and sleep with depression in college students. Journal of American College Health, 2020;68:557-64. https://doi.org/10.1080/07448481.2019.1583653

35.Abdulah DM, Musa DH. Insomnia and stress of physicians duringCOVID-19outbreak.SleepMedicine:X,2020;2:100017. https://doi.org/10.1016/j.sleepx.2020.100017

36.Boksem MAS, Tops M. Mental fatigue: Costs and benefits. Brain Research Reviews, 2008;59:125-39. https://doi.org/10.1016/j.brainresrev.2008.07.001

37.Ishii A, Tanaka M, Watanabe Y. Neural mechanisms of mental fatigue. Reviews in the Neurosciences, 2014;25(4): 469-479. https://doi.org/10.1515/revneuro-2014-0028

38.Dalley JW, Roiser JP. Dopamine, serotonin and impulsivity. Neuroscience, 2012;215:42-58. https://doi.org/10.1016/j.neuroscience.2012.03.065

39.Kringelbach ML, Berridge KC. Towards a functional neuroanatomy of pleasure and happiness. Trends in Cognitive Sciences, 2009;13:479-87. https://doi.org/10.1016/j.tics.2009.08.006

40.Todd AI, Bennett AI, Christie CJ. Physical implications of prolonged sitting in a confined posture-a literature review. Ergonomics SA: Journal of the Ergonomics Society of South Africa, 2007. 19(2): 7-21.

41.Myrtveit SM, Sivertsen B, Skogen JC, Frostholm L, Stormark KM, Hysing M. Adolescent Neck and Shoulder Pain-The Association With Depression, Physical Activity, Screen-Based Activities, and Use of Health Care Services. Journal of Adolescent Health, 2014;55:366-72. https://doi.org/10.1016/j.jadohealth.2014.02.016 
Information about the author:

Yusuf Soylu; https://orcid.org/0000-0003-0609-0601; soylusyusuf@gmail.com; Faculty of Sport Sciences, Tokat Gaziosmanpasa University; Tokat, Turkey.

Cite this article as:

Soylu Y. The psychophysiological effects of the COVID-19 quarantine in the college students. Physical Education of Students, 2021;25(3):158-163.

https://doi.org/10.15561/20755279.2021.0303

This is an Open Access article distributed under the terms of the Creative Commons Attribution License, which permits unrestricted use, distribution, and reproduction in any medium, provided the original work is properly cited http://creativecommons.org/licenses/by/4.0/deed.en

Received: 12.04.2021

Accepted: 27.05.2021; Published: 30.06.2021 